\title{
Cultural reciprocity in special education: Building bridges to cross-cultural understanding with parent ${ }^{*}$
}

\author{
Özel Eğitimde Kültürel Karşılıklılık: Ebeveynlerle kültürlerarası anlayış \\ geliştirmek
}

Elizabeth Harry ${ }^{1}$

\begin{abstract}
Article History
Received : 01 February 2018

Revised : 13 February 2018

Accepted : 14 February 2018

Article Type

Review Article
\end{abstract}

\begin{abstract}
Cultural reciprocity is an approach that goes beyond the concept of cultural competence. The first step for service providers in a multicultural environment is to acknowledge that they cannot be competent in the cultures of all the families they serve. By recognizing the cultural assumptions and biases that underlie their own practice, service providers can then be open to learning about the beliefs of family members, and can engage in an exchange of cultural views. With mutual respect established, providers can collaborate with families in establishing and pursuing realistic goals for the children they serve.
\end{abstract}

Keywords: Special education, families, diversity, cultural competence, cultural reciprocity

Öz: Kültürel karşılıklılık, kültürel yeterlilik kavramının ötesinde bir yaklaşımdır. Çok kültürlü bir ortamdaki hizmet sağlayıcılar için ilk adım, hizmet ettikleri ailelerin tümünün kültürlerinde yetkin olamayacaklarını kabul etmektir. Kendi pratiklerinin altında yatan kültürel varsayımları ve önyargıları fark etmek suretiyle servis sağlayıcılar, sonra aile üyelerinin inançlarını öğrenmeye açık olabilir ve kültürel görüş alışverişinde bulunabilirler. Karşılıklı saygı kurulduğunda, hizmet edilen çocuklar için gerçekçi hedefler belirleme ve bunları takip etme konusunda ailelerle işbirliği yapabilirler.

Anahtar Kelimeler: Özel Eğitim, aileler, çeşitlilik, kültürel yeterlilik, kültürel karş1lıklılık

\footnotetext{
* Presented as "Keynote Speech" at 5th International Early Childhood Education Congress

${ }^{1}$ University of Miami, School of Education and Human Development, Department of Teaching and Learning, bharry@miami.edu
} 


\section{INTRODUCTION}

I will begin this paper in a very personal tone, because I believe that the work we do with the families of children with disabilities is always personal. While we must develop professional personas that utilize the skills and knowledge of our field, without intra-personal and interpersonal awareness we will not succeed in reaching the most important people in children's lives - their families.

\section{Daniel, the Steel-pan Player}

I begin by playing a video to introduce you to a wonderful young musician, Daniel Gulston, from Trinidad. You will be inspired by the music of the Beatles' song "Imagine". You will also be inspired by the fact that Daniel has Down Syndrome, and that his musical talent and skill defy all the stereotypes we hold of persons with that condition. In the video you will see him playing the steel drums, alongside his father and brother.

Daniel's parents Diane and Dane, told me about their reactions when Daniel was born:

Diane: From the first day it was hard! I couldn't bring myself to accept the fact that I could bring a childlike that into this world. When the doctor saw Daniel she said, "My goodness, Dianne, we have to talk!" I said, "Doctor what's wrong?" She said, "As far as I'm concerned nothing is wrong, this is God's work." She started to explain that Daniel would be diagnosed with Down syndrome. I held on to her and cried...

But my husband, I pulled strength from him.

Dane: I knew Dianne was scared because she hardly talked about it. Pride. People feel like it's a kind of embarrassment to walk with the child. But that really wasn't my thinking at all. God is good. I really didn't see the difference at first. And now it's totally the opposite. Daniel is a star! If you go anywhere in the country - people shout: "Look! My boy!" We don't have a clue who the person is, but they're seeing him performing all the time.

Like Diane, I also experienced the shock of disability when my first child, Melanie, was born with cerebral palsy. I was living in Trinidad at the time, and experienced many of the same feelings that Daniel's mother described. Fortunately, I was a teacher by training and by instinct, and since special schools for children with disabilities at that time in Trinidad did not accept children under the age of 5, I decided to start a small private school for children like Melanie. The school, the Immortelle Children's Centre, started with 8 children, and went along very well 
for some years, but sadly, Melanie died at the age of 6 . I continued in the school, but after a few years I decided to go the U.S. to study for the Ph.D. degree in special education. I turned the school over to the parents, who formed a not-for-profit organization, and continued to operate the school from then till now. The school now serves about 70 children and receives support from the government, which was not the case when I was there. Daniel, the musician, is a student at that school. I consider the Immortelle to be Melanie's contribution to her community. This background led me to make family issues the focus of my doctoral studies. Also, living in the U.S., I became very aware of the importance of my racial and ethnic identity, and decided to focus my studies on the experiences of parents from diverse backgrounds in the U.S. So I will draw on my own research in the US, Spain, and Trinidad, as well as the findings of other researchers who have focused on family issues.

\section{Parent Participation as a Central Principle in Turkey and the USA}

A review of the services for children with disabilities in Turkey reveals great similarities to those in the U.S. Most notably, both countries share the following principles:

- Services for all children

- Early intervention

- Parent participation

- Individual Education plans

- Least restrictive environment

- Inclusion as a goal

- Regional Centers for assessment and placement

Of these principles, I will focus on parent participation and will consider some of the challenges of communication with families from diverse cultural and ethnic backgrounds. Like the U.S., Turkey is challenged with meeting the needs of many diverse groups, whether native or immigrant. Turkey is known for its tremendous commitment to alleviating human suffering, so many of my comments are in the context of the generous support that Turkey is currently giving to refugees from Syria and Iraq.

I understand that Turkey's plan is to begin to integrate children of these immigrant groups into the regular public education system soon. From our experience in the US, I would say that there will be one key thing to take into account: Approaching the children and families with a clear understanding that their language, cultural, and contextual differences do not indicate deficiencies or disabilities. This has been a problem for us in the U.S. - a tendency to be too 
quick to interpret a difference as a deficit and, consequently, to send children for evaluation for learning disabilities without taking into account the influence of culture and context on children's learning. There has been a tendency also to devalue parents' views and child-rearing practices, assuming that they are deficient because they differ from ours.

So I will focus on some ideas for reciprocal communication between professionals and parents from diverse cultures and contexts.

\section{Cultural Competence as Cultural Reciprocity}

Perhaps the best-known concept for professionals in cross-cultural situations is "cultural competence": The challenge of learning to be competent in the cultures of the families you serve. Some professional training programs focus on learning the interpersonal behaviors common in various cultures. While it is good to have such background knowledge, in very diverse societies such as the U.S., and currently, Turkey, this is increasingly difficult because there are so many cultural groups, both native and immigrant. So for example, some people shake hands on meeting a new person, and some do not. Some believe that direct eye contact is a sign of respect and honesty, while some believe it is a sign of impudence and disrespect. We have the famous example of a child who is naughty in school and casts his eyes to the ground when he is being reprimanded by the teacher. The teacher scolds him, "Look at me when I'm talking to you, boy!" The teacher sends a note home to the parent reporting the child's misbehavior. So that night, when the boy goes home, his father reprimands him and the child looks his father directly in the eye as he speaks. The parent says, "Don't you dare look at me when I'm correcting you, boy! Show some respect!"

So what should a teacher do?

Maya Kalyanpur and I (Kalyanpur and Harry, 2012) have introduced the concept of Cultural Reciprocity - a somewhat different way of learning to be "competent". By reciprocity, we mean respectful, two-way communication and sharing of information. We argue that we cannot really be culturally competent unless we behave in a reciprocal manner. One-way competence is not competence! When we are reciprocal, we are in a posture of learning. We are learning about the parents' perspectives and they are learning about ours. Therefore, the most important thing is to acknowledge that we are mostly incompetent in unfamiliar cultures; that we know little but want to learn a lot about the "other's" culture. We recommend that we start by understanding culture at its deepest, rather than its most superficial levels. In other words, if we can recognize the beliefs, values, and priorities, that underlie our behaviors, we will be able to approach all 
people with respect for what we share as human beings, rather than be alienated by outward behaviors that may look different from our own.

\section{Four Steps of Cultural Reciprocity}

We recommend approaching cultural reciprocity by being conscious of four steps. While these steps are not discrete and may overlap, the important thing is to be keenly conscious of these four processes. First, we begin our reciprocal approach by looking inward and noticing that our own beliefs are culturally based. Next, we seek to understand the cultural assumptions and beliefs in the other person's understanding of the issues. Third, recognizing that we are all operating from some cultural base, different but not superior, we explain our beliefs and practices, rather than assuming that the other person should know and share them. Finally, we work collaboratively to establish goals that are shared by both the parent and the professionals. I will develop each of these steps below.

\section{Step 1: Personal Reflection}

First, I must ask, "How do I feel about this parent? Why?" For example, we ask ourselves whether we see this parent as a competent parent. Why or why not? Is it because I am stereotyping the parent because of their educational level or current societal or immigrant status? Or perhaps because the group this parent belongs to has a negative reputation in the society? I need to pay attention to this feeling so that I can dismiss it and remain open to this individual parent.

Second, what is the basis of my assessment of and recommendation for the child? What personal biases or cultural assumptions are my recommendations based on? Do I value the everyday knowledge that the parent has of the child? Or do I only value the scientifically based knowledge that is the source of my own professional training

For example, I ask myself why I am recommending an early intervention therapeutic program for the child? I will probably find that I'm basing this on my belief that young children's disabilities can be lessened by physical therapies and by language and social stimulation because I believe that the brain is most responsive when the child is young. However, the parent may not share this belief! The parent may believe that there is a spiritual condition that needs to be addressed.

Overall, in my personal reflections I need to try to be conscious of both my culture and the influence of my professional training on my assumptions and to stay open to the possibility that the parent may have knowledge I do not have. 


\section{Step 2: Invite, Listen to, and Respect the Parent's Views}

Our research on diverse cultural groups shows that parents may have different definitions of various disabilities. These differences can lead to disagreements that, if not addressed, can result in an unnecessary breakdown in communication. There are several common trends in this respect.

Differences in definitions. When are differences in a child's development significant enough to be defined as a disability? Or, what are the appropriate treatments for the child's condition? Different groups may hold different definitions of what constitutes a disability and its appropriate treatment.

For example, in the milder disabilities, such as "learning disabilities" that have to do with reading or other academic subjects, it is easy to see that differences in definitions of the condition can depend on parents' educational and academic background, as well as their socioeconomic status and the expectations the family holds for their children. So, if literacy is not a crucial requirement for success in that family's community, or if the family is not highly literate themselves, then poor reading may not be seen as meaning there is a problem with the child's learning.

This can also occur with definitions of mild intellectual impairment: For example, a professional may describe a child as having an "intellectual disability" (ID) because her scores on an IQ test or on academic measures fall below a certain point. However, parents might not see this as a problem because they may be more concerned with the child's social and overall communication development than with academic progress. For example, Puerto Rican parents in my study (Harry, 1992) rejected the definition of "mental retardation" saying that their child could communicate adequately in both English and Spanish and was very well behaved socially. For them the child would have to be much more impaired than this to be called "retarded". One grandmother defined that condition this way:

Retarded is when you can't walk or talk, or have some really serious problems. But my granddaughter has nothing like that, she talks in both English and Spanish and she's very well behaved.

From the professionals' point of view, however, the child, who was about age 7, was designated "retarded" because, although she did use both languages, her language level was evaluated as being about that of a 4-5 year old. 
This is not just a process that occurs when you cross cultures, but also can occur within a given culture over time. For example, in the U.S., up until about 1969, the American Association on Mental Retardation used a cut-off IQ score of 85 to determine mental retardation. So anyone falling below 85 would receive that label. However, in 1969 the Association changed its definition - reducing the cut-off score to 70 ! So, with the stroke of a pen, the definition of Mental Retardation changed overnight. This provokes the obvious question of whether individuals described as mentally retarded prior to this decision should still be considered so. To put this more facetiously, should the change in definition actually be seen as a cure for the condition?

These examples indicate that, except for the most extreme or obvious disabilities, many conditions that are called disabilities are determined by society. This is what we mean when we say that societies construct what they mean by a disability. We refer to this as the "social construction" of disability.

Differences in interpretations of the causes of the condition. Besides different definitions, parents may also hold different interpretations of the child's disability. The question here is, what is the underlying belief on which parents and professionals base their interpretation? For example, some of the following have been noted by cross-cultural researchers:

- The disability represents a scientific, biological occurrence

- The disability represents a reward or a gift from God

- The disability represents a punishment from God

- The disability represents a sign of evil-doing

- The disability is a signal that the family is inherently bad.

We know that, because most professionals base their understanding of disabilities on the first explanation - a belief in science - they seek scientific, biological explanations for conditions and their treatments. By contrast, if parents are basing their explanations on spiritual or social beliefs, they may initially reject professional evaluations or recommendations. I think of the example of a Hmong family in the U.S. who were taken to court for refusing to allow surgery on their son's club feet because they believed that this condition was a blessing, a reward for the trials suffered by a warrior ancestor who had been wounded in battle. More common examples would be of families with deep religious beliefs who may see the condition as "God's will", which should not be challenged or interfered with. 
Such differences in beliefs can result in different reactions to the diagnosis. It is common to hear professionals refer to parents as being "in denial" because they doubt or disagree with a diagnosis. While "denial" may be a natural initial response by many parents, this is a dangerous assumption because it presumes that the professional is right and the parent is wrong, which may not be the case at all. I believe it would be more accurate to describe the parent as being "in disagreement", rather than "in denial".

\section{Step 3. Engage in Full Reciprocity with Parents by Explaining Professionals' Assumptions and Beliefs}

Having listened without judgment to the parent's perspectives, it is essential for us to respect that this is the parent's belief. We do not have to share the belief! Very often we won't! But now it is our turn to explain our views, which we have usually learned partly through our own experience but also through our professional training. We should not assume that the parent should know or share our beliefs. Rather, we explain to them the basis on which we are approaching the child's condition.

So, without contradicting the parents' statements, we can genuinely explain the basis of our professional beliefs. For example, that the educational approach is based on a belief in scientific study, which is not to deny that there may be other powers, such as spiritual powers, at work. But we can explain there is a lot of research done with children with disabilities that shows that there are therapies or instructional approaches that will help. So even though the condition may have been determined by a higher power, this does not mean that the child was not meant to develop and improve. In this step it is crucial to explain the requirements and processes of the educational system to parents from diverse cultural contexts, as their experience of schooling might be very different.

Here, cultural reciprocity calls for us to accept the remedies that the parent believes in (as long as they're not harmful to the child), and present the scientifically based recommendation as an important addition, which has been shown to be helpful to children. Most parents will not refuse an additional treatment, as long as their deeply held beliefs are also respected. We explain also any relevant bases of our recommendations, which may include legal or professional requirements in the delivery of services.

\section{Step 4: Collaborating Reciprocally}

The outcome of reciprocal understanding should be genuine collaboration. There are several challenges facing professionals at this point. One of these is the obvious challenge of different 
beliefs and practices that I have been illustrating throughout this process. But another, more hidden reason is that most of us have been trained to assume that our role is to give information and advice, and that the parents' role is to listen and follow instructions. Yet, at the same time, we state that parent participation is one of our goals. Moreover, in the U.S., we state this as a goal because of our beliefs in individual rights and equality: the principle that each individual has the right, and is expected, to be, an equal partner. But many parents, especially from societies where there are firm social hierarchies, really do not hold this principle. So the issue of collaboration is challenging for both parents and professionals.

Here, I feel that it's up to professionals to try to build the bridge. If we can truly practice the first 3 steps of the cultural reciprocity process, then we will be ready for collaboration. We will have identified our own biases and beliefs, and learned about the parent's underlying beliefs, so will now be better able to plan together with the parent in a reciprocal way.

The surest way to proceed here is to ask the parent to identify an area of the child's development where they would like to see some improvement, and decide with them to start at that point. The parent may say they want the child to walk, or talk, or be more independent. I give independence as an example that's very common in individualized education programs in the US. It may be so in Turkey also, but I suspect that the specific ways in which the child is expected to become independent will vary a lot from culture to culture.

For example, in the U.S., self-feeding, weaning, is considered very important and expected at a young age. I share the example of an interaction between an early childhood professional and a mother of a 3-year old child with delayed development. The professional was becoming frustrated that the mother never seemed to follow through on her recommended goal of selffeeding - learning to hold the spoon and cup. Finally, the professional, remembering that her own underlying assumption was a belief in fostering the child's independence, asked the mother, "Well, don't you want the child to become more independent?" The mother replied that the most important thing facing her right then with the child was that the child was so dependent on her she could not leave the child with her aunt even to go shopping for food. This information made it evident that independence was important to this mother, but the interpretation of what that meant was different from the professional's. The mother and the professional then set about planning specific steps to "wean" the child gently away from full-time dependence on her mother. She could begin by having the aunt stay with the child for just a few minutes at a time while the mother was cooking, and then move forward step by step by step. This was far more important to the mother than her child's self-feeding. 


\section{Challenges of Oral and Written Communication}

As we proceed toward becoming more reciprocal in our interactions, we need to pay close attention to our assumptions about what kind of language we should be using. Here I will comment on two main aspects of this: Professional jargon and written communication.

\section{Professional Jargon}

This can be a huge problem in our communication with parents. Because we base our understanding of disability on medical principles and practices, we become accustomed to using very technical language when we discuss disabilities. I suspect that we also like that language because it sounds "professional", which, unfortunately, often means that only members of our group - our "club" - know what we're talking about!

Abstracted terminology. Two tendencies stand out in the way we use this language. One is the use of abstracted terminology rather than words that name the actual thing we're referring to. For example, in the U.S., professionals frequently refer to young children using "manipulatives" - a generalized word for a wide range of toys and materials that children can manipulate. But this term means nothing to the average parent, since no-one speaks of toys in this way. Normally, we talk about blocks, toy cars, puzzles, and so on. Yet, we often hear professionals telling parents that the children are using "manipulatives".

Medicalized language. Another tendency is to use medically based terminology for everyday human functions. For example, "auditory" for what we hear; "visual" for what we see; and "perceptual" for what we interpret when we see something. So, for example, I once observed an Individualized Education Plan meeting for a child, in which the speech/language pathologist was giving her report. She said that the child "has an auditory processing deficit". One of the other professionals on the team tried to clarify this so the mother would understand. So she asked the therapist to explain the matter in a different way. The therapist replied, "Of course! It just means that the child processes information auditorially!" It seems the professional was so entrenched in her jargon, or else so determined to "sound" professional, that she could not simply say that the child learned best by listening!

This kind of incomprehensible jargon has the effect of alienating parents by making them feel that they cannot communicate with these very educated people! As a result parents often have very little to say in these conferences.

\section{Written Communication}


As professionals, we rely a great deal on written communication. While we do have to keep accurate records, it is important to recognize that good oral communication has to be the basis of our communication with many parents. This is partly because many parents may not have the level of literacy needed to make sense of many professional documents, and partly because the very fact of parents receiving written information about their child can be intimidating because it is so formal and so impersonal.

For example, in my study with Puerto Rican parents, a mother called me one day in great distress. She said, "They sent me a letter! I know what it says, but I don't know what it means!" First of all, when she said "they sent me a letter", she really meant that she did not know exactly who it came from. She knew it was from the school district, but it was not signed by anyone she knew, such as the child's teacher or the principal. So this impersonal message about the most personal thing in her life - her child - was to her, fearful and intimidating. In addition, she really did not understand the jargon that was used throughout the letter.

I also want to note that there is a real danger in piling up written information on children! While a child's dossier may be useful, the more that is written, the more we tend to place a value of objective truth on the information, often forgetting that earlier findings might have been mistaken!

\section{Participation Structures}

My final point for Step 4 of the cultural reciprocity process relates to what we can call "participation structures". Meaning, how we structure the participation within a group. In the U.S., the usual way of conducting parent conferences, for example, to discuss a child's Individualized Education Plan, is for the parent to sit down with a team of professionals, which may include the teacher, a counselor, a speech/language or occupational or physical therapist, and very often a psychologist. There have been many studies of how parent participation looks in this kind of meeting. To summarize, the main points noted are:

\section{Inequitable parent vs. professional introductions}

Here we notice that the parent is often introduced as "mom" or by her first name, while the professionals are all introduced by their titles and last names (Dr., Mrs. Miss etc). While this may be normal practice in societies that are more hierarchical, in the U.S. it is very noticeable because the communication styles among American professionals tends to be quite informal, often using first names even among strangers. Yet, somehow, in these meetings, the 
professionals tend to receive quite formal treatment while the parents are addressed by first names.

\section{The order, style, and timing of reports}

Often, the structure of the reports tends to alienate and silence parents. Research on these conferences show a clear pattern of the first report being given by the psychologist, usually in very formal, technical language, which many people present do not understand, and certainly not the average parent! This is followed usually by any other "medical" or therapeutic professionals before the teacher gets her turn to report. This can be a source of discomfort for parents since the teacher is usually the only person in the room whom they know. Moreover, this sequence of information has the effect of silencing parents, since they may have understood very little of what was said. Clearly, this is a very bad way to feel since parents most likely believe that they know the child better than everyone! Yet they find themselves speechless and, when asked if they have anything to say, their most likely answer will be "No!

\section{Disrespectful, inattentive interactions among team members}

Professionals on these teams sometimes fail to be fully involved beyond their own reporting. Consequently, they often begin talking to each other during someone else's report, or pass around papers to be signed while the parent is speaking. This is disrespectful to the parents and also means that these professionals are not really learning all they need to know about the child.

\section{Children or unprepared adults as translators}

Finally, I am sure that translation will present challenges for Turkish professionals working with immigrant families. There are many things to be said about the technicalities of translation, but one pervasive problem is the shortage of competent adult translators for meetings with families. As a result, siblings of children with disabilities are frequently used as translators. While this may seem quite a natural and convenient thing to do, it has the effect of putting the sibling into the position of a parent or adult, which can create quite an imbalance in the family because the sibling then becomes more knowledgeable of the school processes than the parent. Another reason not to use siblings, of course, is that the sibling, also being a child, may not be a very reliable translator, and may be caught between his perceptions of needing to be loyal to the family and needing to "say the right thing" for his teachers. It is important for school districts to place a high priority on translators who are both culturally and linguistically competent in the language of the families.

\section{The Importance of Well-trained Therapists}

$$
\begin{aligned}
& \text { Erken Çocukluk Çalışmaları Dergisi } 2018 \text { Journal of Early Childhood Studies } \\
& \text { Cilt 2·Say1 2· May1s } 2018 \text { Volume } 2 \cdot \text { Issue } 2 \cdot \text { May }
\end{aligned}
$$


I will end my presentation on quite a personal note. All that I have said about cultural reciprocity is most important in early childhood, because that is the period in which the child is most responsive to intervention and when the family is laying its foundation for a trusting relationship with the professional services on whom they are going to rely for a long time. So, in early intervention in the U.S., we have emphasized the concept of "family centered" services, and here the Individualized Education Plan is actually referred to as an "Individualized Family Service Plan". This makes the point that for the child to thrive, the family needs also to thrive. Recently, the family focus has led to an emphasis on delivering services in the most "natural environments" - that is, environments in which the child is naturally spending her time. This may be the home, or a day-care center, or a family member's home. However, it can also mean a special education center, if that is the environment that is most "natural" for that child.

I certainly support this approach. However, there is one point I want to make about the "natural environments" focus: I am concerned that a home-based focus should not be interpreted as meaning that the parent will be expected to become the service provider. While I do believe that it is essential to teach parents the principles of intervention, whether it be for speech/language development, physical development, or cognitive development, I also know from my own personal and professional experience that there is nothing like a skilled therapist or teacher.

My daughter, Melanie had cerebral palsy of the "athetoid" type, which made her movements "floppy" and uncoordinated. When I started the little school for children with disabilities in Trinidad, I was fortunate to have as a partner a very skilled physical therapist, who provided Melanie with daily therapy from the age of about 3 to 4 . My experience of Melanie's dramatic progress during that time convinced me that therapeutic services should not be diluted. I know that there is a shortage of therapists in Turkey, so I respect the fact that this might be hard to provide, but I do encourage you to place as strong a focus as possible on training in the therapies.

In conclusion, it has been my extreme pleasure to have the opportunity to share with my Turkish colleagues some of the insights I have gained over my years as a parent, teacher, and researcher. In the spirit of reciprocity, I must also acknowledge that I have learned a great deal from my short time in your beautiful country. Perhaps most important, I have been impressed by the warmth and hospitality of the Turkish people and their culture. I believe that this national characteristic will ensure that cultural reciprocity will not be hard for professionals to master as they work with newcomers who are in need of your generous and thoughtful support. 


\section{REFERENCES}

Kalyanpur, Maya, and Harry, Beth. (2012). Cultural reciprocity in special education: Building family-professional relationships. Baltimore: Brookes. 